\title{
Perancangan Sistem Monitoring Ketinggian Air Sebagai Pendeteksi Banjir Berbasis IoT Menggunakan Sensor Ultrasonik
}

\author{
Nicko Pratama, Ucuk Darusalam*, Novi Dian Nathasia \\ Fakultas Teknologi Komunikasi dan Informasi, Informatika, Universitas Nasional, Jakarta, Indonesia \\ Email: ${ }^{1}$ Nickoprata80@ @mail.com, ${ }^{2, *}$ ucuk.darusalam@gmail.com, ${ }^{3}$ novidian@civitas.unas.ac.id \\ *) Email Penulis Korespondensi: ucuk.darusalam@gmail.com
}

\begin{abstract}
Abstrak-Curah hujan yang tinggi pada musim penghujan dapat berlangsung sekitar enam bulan, hal ini membuat hujan terus menerus dan meyebabkan meningkatnya volume air yang berpotensi terjadinya banjir. Sedangkan masyarakat tidak mendapat informasi atau pemberitahuan secara langsung ketika hal tersebut akan terjadi. Untuk mengantisipasi permasalahan tersebut, perancangan sistem monitoring ketinggian air sebagai pendeteksi banjir secara dini berbasis IoT dinilai efisien. Sistem akan mendeteksi jarak sensor dengan permukaan air, jika jarak permukaan air mendekati sensor maka sistem akan membunyikan sirine sebagai pertanda akan terjadi banjir. Sistem akan menampilkan status siaga yang terjadi dan jarak permukaan air secara realtime. Dari 100 data jarak permukaan air dengan sensor ultrasonik yang telah diujicoba, mendapat 6 kali kesalahan pembacaan jarak. Pada pengujian dari beberapa jarak permukaan air dengan sensor, sistem dapat menyimpan semua data jarak ke dalam database.
\end{abstract}

Kata Kunci: Monitoring, Banjir, Sensor Ultrasonik, IoT.

\begin{abstract}
High rainfall in the rainy season can last about six months, this makes it rain continuously and cause an increase in the volume of water that has the potential for flooding. While the public does not get information or notice directly when it will happen. To anticipate these problems, the design of a water level monitoring system as an early flood detection based on IoT is considered efficient. The system will detect the distance of the sensor to the surface of the water, if the distance of the surface water approaches the sensor, the system will sound the siren as a sign of flooding. The system will display the alert status that occurs and the water surface distance in realtime.. From 100 data of water surface distance with ultrasonic sensors that have been tested, get 6 times the distance reading error. In testing of several water surface distances with sensors, the system can store all distance data into a database.
\end{abstract}

Keywords: Monitoring, Flood, Ultrasonic Sensor, IoT.

\section{PENDAHULUAN}

Indonesia adalah negara yang terletak di asia tenggara yang memiliki dua musim, yaitu musim hujan dan kemarau karena merupakan kawasan beriklim tropis. Pada musim penghujan, curah hujan sangat tinggi dan dapat berlangsung hingga enam bulan. Hujan yang terus menerus menyebabkan meningkatkan volume air, hal ini berpotensi terjadinya banjir di beberapa daerah. Jika terjadi banjir masyarakat akan mengalami kerugian. Sedangkan masyarakat tidak mendapat informasi atau pemberitahuan secara langsung ketika hal tersebut terjadi.

Peneliti sebelumnya telah melakukan penelitian tentang sistem peringatan dini bahaya banjir. Penelitian oleh Indah Fitri Astuti merancang sistem pendeteksi banjir menggunakan mikrokontroler Arduino Uno ATMega328, sensor ultrasonik untuk mendeteksi jarak, LCD menampilkan informasi jarak, buzzer sebagai pemberitahuan status siaga, gsm modul sim800L sebagai sistem sms gateway[1]. Penelitian oleh Indri Handayani merancang sistem pendeteksi banjir menggunakan mikrokontroler Arduino Uno, sensor ultrasonik HC-SR04, LCD dengan modul I2C, buzzer, gsm modul sim900[2].

Penelitian oleh Lilian Efendi merancang sistem pendeteksi banjir menggunakan Arduino Uno R3,modul gsm 800L,sensor ultrasonik HC-SR04,dan modul GPS digunakan untuk menerima dan menentukan titik lokasi[3]. Penelitian yang dilakukan oleh Sofyan merancang sistem pendeteksi banjir dengan menggunakan Arduino Uno R3, sensor ultrasonik, buzzer[4].

Penelitian oleh Jonshon Tarigan merancang pendeteksi banjir secara dini menggunakan Arduino Uno, LCD, dan sensor potensiometer untuk mendeteksi apakah ketinggian air mencapai level terjadinya banjir[5]. Penelitian yang dilakukan oleh Achmad Muzakky merancang sistem pendeteksi banjir dengan menggunakan modul NodeMCU ESP8266 sebagai pemroses dan mengirimkan data secara nirkabel, sensor water level, buzzer, aplikasi Blynk digunakan untuk menampilkan pemberitahuan status ke android[6].

Penelitian oleh Erwan Rahmadi merancang sistem pendeteksi banjir menggunakan Arduino Uno, modul gsm WAVECOM sebagai sistem sms gateway,dan konverter RS232 yang digunakan untuk menghubungkan modul arduino dengan modul lainnya[7]. Penelitian yang dilakukan Widy Astuti merancang sistem pendeteksi banjir menggunakan Arduino ATMega 328p, modul gsm sim800L, buzzer, dan sensor kapasitif yang terbuat dari dua buah lempeng PCB yang diberi batas-batas tertentu untuk mengukur ketinggian air[8]. Penelitian oleh Riny Sulistyowati merancang sistem pendeteksi banjir menggunakan Arduino ATMega 8535, sensor ultrasonik, buzzer, LCD, modem WAVECOM[9]. Penilitian yang dilakukan oleh Angga Prasetyo dan Moh.Bhanu Setyawan merancang sistem kewaspadaan banjir menggunakan Mikrokontroler Rasberry Pi, senor ultrasonik, dan aplikasi telegram sebagai media penyampaian informasi[10].

Berdasarkan penelitian yang telah dilakukan oleh peneliti sebelumnya terdapat beberapa permasalahan diantaranya adalah mengetahui ketinggan permukaan air dan pemberitahuan status siaga kepada masyarakat, maka 
dirancanglah sistem monitoring ketinggian permukaan air sebagai pendeteksi banjir. Sistem tersebut dirancang menggunakan sensor ultrasonik untuk mendeteksi ketinggian air. Berikutnya sistem akan mengirimkan data jarak ke dalam server untuk disimpan pada database MySQL secara realtime sebagai laporan. kemudian data yang terbaru akan ditampilkan di dalam halaman website dan LCD.

\section{METODE PENELITIAN}

Metode penelitian adalah kegiatan mengumpulkan data atau informasi yang berhubungan dengan penelitian sejenis untuk dapat merancang sebuah sistem. Dalam sebuah perancangan sistem dibutuhkan sebuah metode penelitian agar proses penelitian berjalan dengan baik dan mencapai tujuan dari penelitian. Metode penelitian ini dapat dilihat pada gambar 1 .

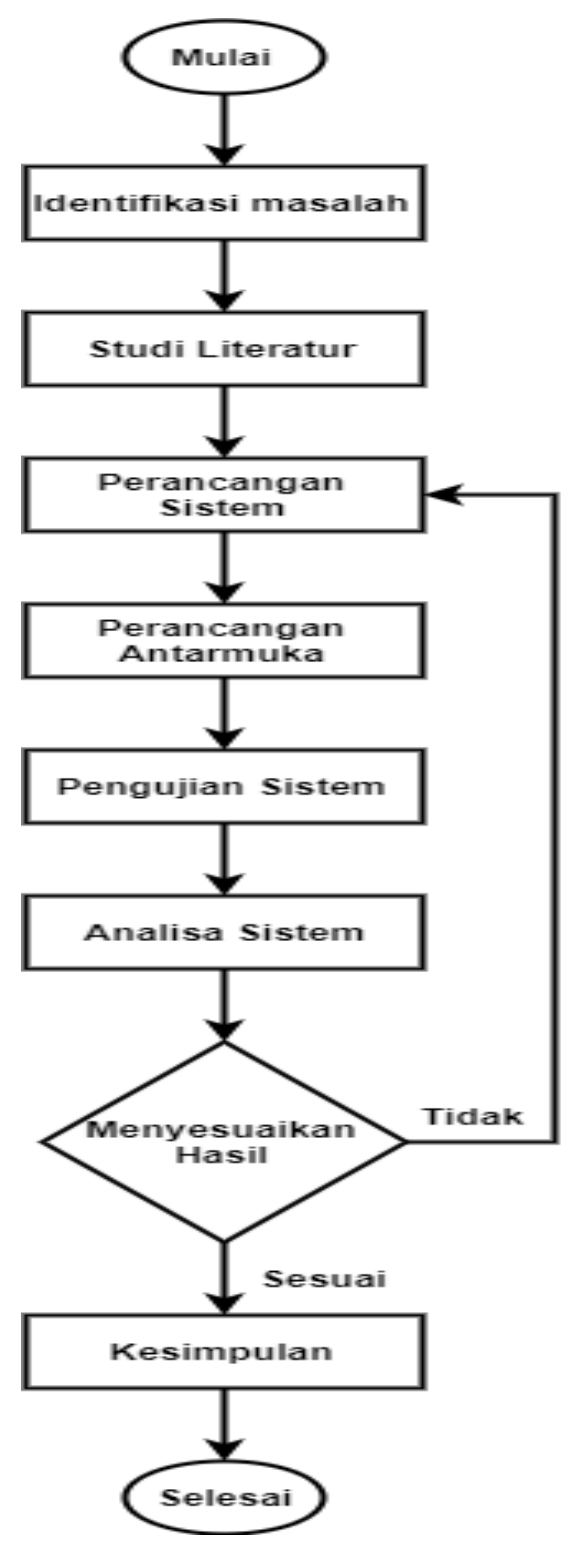

Gambar 1. Flowchart Metode Penelitian

1. Identifikasi masalah adalah kegiatan menganalisis masalah banjir yang sering terjadi di beberapa wilayah, sehingga masyarakat mengalami kerugian mulai dari material dan korban jiwa. Selain itu mereka juga tidak mengetahui kapan akan terjadinya banjir.

2. Studi literatur dilakukan untuk mendapatkan informasi mengenai bahan seperti sensor ultrasonik, mikrokontroler dan modul lain dengan mempelajari berbagai acuan dari jurnal-jurnal penelitian sebelumnya yang sesuai dengan materi penelitian. Dan juga berfungsi untuk membuat sistem lebih efisien sehingga mengurangi kesalahan dan meningkatkan hasil dari penelitian ini.

3. Pada tahap perancangan sistem akan menjelaskan tentang alur proses dan langkah langkah operasi yang ada dalam sistem dengan menggunakan flowchart. Mulai dari proses menghubungkan ke internet, proses 
Available Online at https://ejurnal.stmik-budidarma.ac.id/index.php/mib DOI 10.30865/mib.v4i1.1905

pembacaan jarak, proses pengiriman data jarak ke server, penyimpanan data ke database, pembacaan kondisi status, dan proses menampilkan data ke user interface. Berikut adalah gambar flowchart sistem yang dirancang:
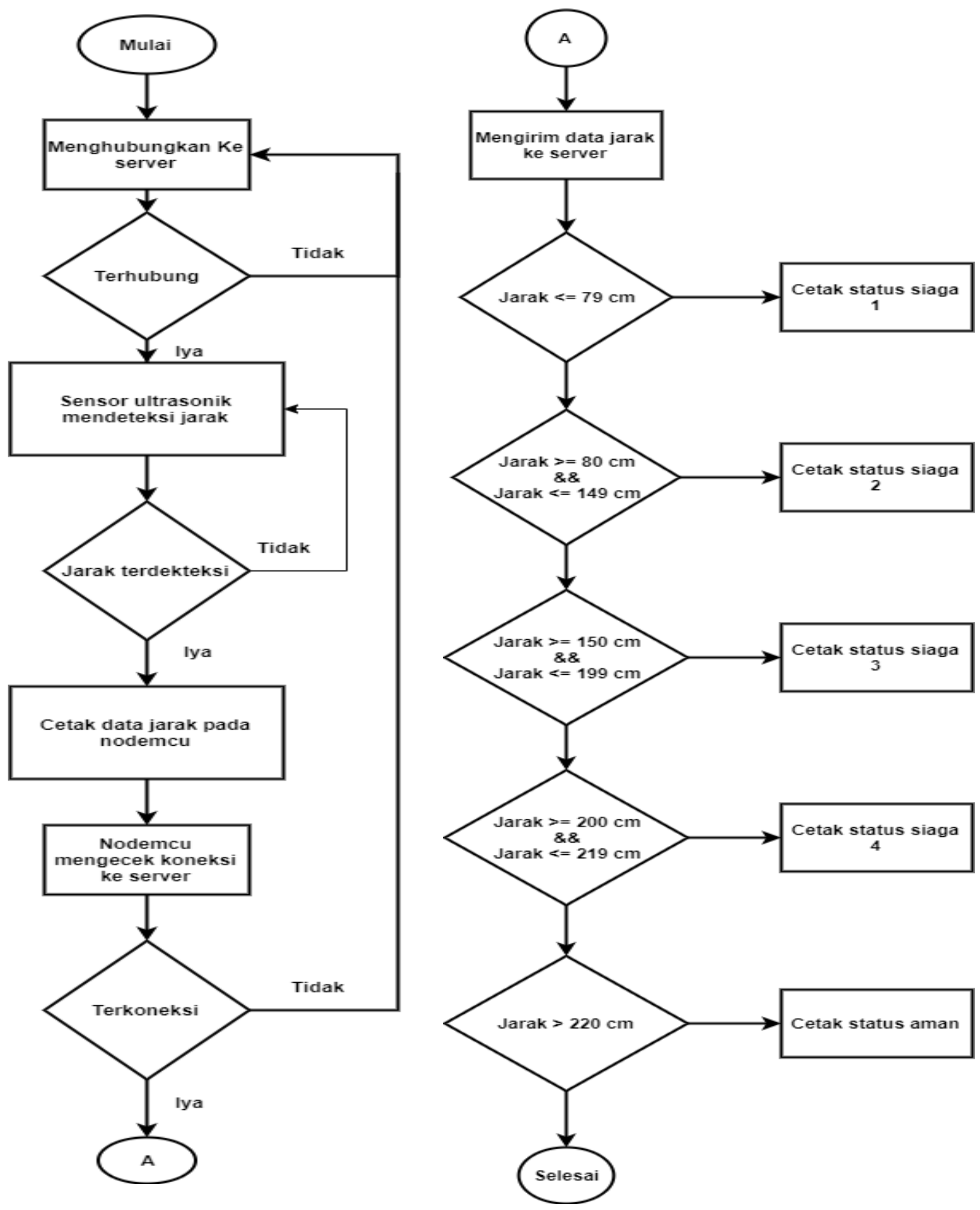

Gambar 2. Flowchart Proses Pendeteksi Banjir

Pada gambar 2 menjelaskan tentang sistem diawalin dengan melakukan koneksi ke server, selanjutnya sensor ultrasonik akan membaca jarak ketinggian permukaan air, setelah sensor membaca jarak maka akan mencetak data pada nodemcu, nodemcu akan mengecek koneksi dengan server, jika terkoneksi maka akan melanjutkan ke proses berikutnya, jika kondisi tidak terpenuhi maka akan kembali ke proses menghubungkan ke server. Berikunya sistem akan membaca kondisi yang sesuai dengan jarak, jika kondisi terpenuhi maka akan mencetak data jarak yang sesuai dengan jarak ke dalam website dan LCD 
4. Tahap perancangan antarmuka adalah proses membuat aplikasi monitoring jarak ketinggian permukaan air berbasis website menggunakan PHP dan Bootstrap yang akan menampilkan data jarak dari database. Jika datanya benar maka akan otomatis tersimpan dalam database.

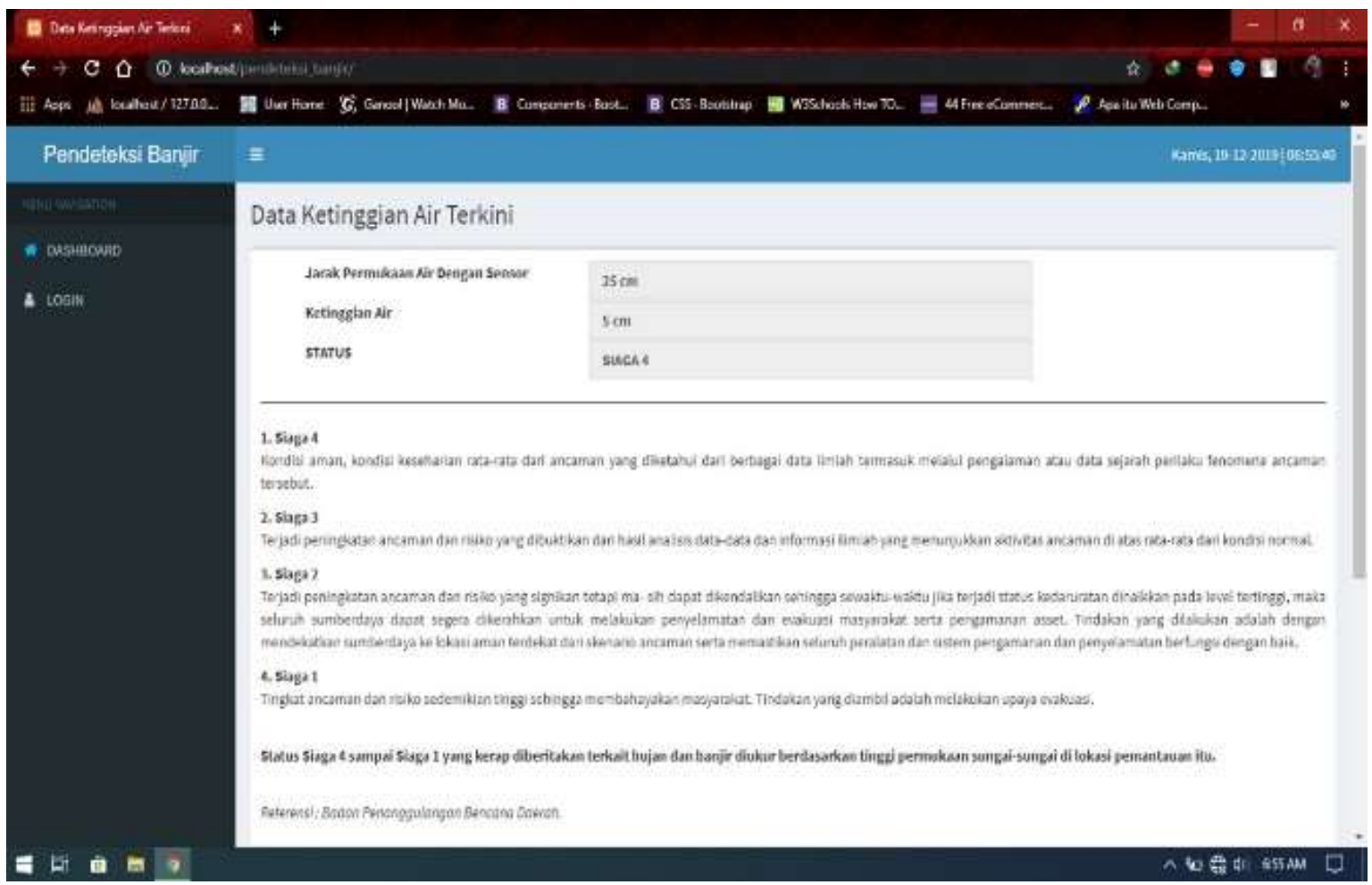

Gambar 3. Tampilan website

5. Pada tahap pengujian dilakukan ujicoba terhadap alat dan aplikasi yang telah di rancang. Data hasil ujicoba akan dicatat sebagai bahan untuk proses analisa.

6. Proses analisa adalah tahap menentukan hasil yang telah di ujicoba, jika hasil sesuai dengan yang diinginkan maka dapat melanjutkan ke tahap kesimpulan, jika tidak sesuai maka akan kembali ke tahap perancangan sistem.

7. Tahap penulisan kesimpulan berisi tentang hasil penelitian dari ujicoba dan analisa yang telah dilakukan.

\section{HASIL DAN PEMBAHASAN}

\subsection{Spesifikasi sensor ultrasonik}

Pada pengujian yang dilakukan untuk mendeteksi ketinggian air menggunakan sensor ultrasonik yang bertipe $\mathrm{HC}$ - SR04. Sensor tersebut memiliki spesifikasi seperti pada tabel 1.

Tabel 1. Spesifikasi sensor ultrasonik HC - SR04

\begin{tabular}{ll}
\hline \multicolumn{1}{c}{ Keterangan } & \multicolumn{1}{c}{ Hasil } \\
\hline Tegangan sumber operasi & $5.0 \mathrm{v}$ \\
Konsumsi arus & $15 \mathrm{~mA}$ \\
Frekuesi operasi & $40 \mathrm{KHz}$ \\
Minimum jarak & $0,2(2 \mathrm{~cm})$ \\
Maksimum jarak & $4 \mathrm{~cm}$ \\
Sudut pantul gelombang pengukur & 15 derajat \\
Dimensi alat & $45 \times 20 \times 15 \mathrm{~mm}$ \\
\hline
\end{tabular}

Pada gambar diatas alat sensor ultrasonic yang bertipe HC - SR04 dapat memembaca jarak minimum $2 \mathrm{~cm}$ dan maksimum $4 \mathrm{~cm}$. sudut pantul gelombang pengukur adalah 15 derajat, dengan cara kerja pin trigger memancarkan gelombang ultrasonik kemudian pin echo menerima hasil pantul gelombang yang mengenai objek

\subsection{Pengujian mengkoneksikan nodemcu dengan internet}

Proses pengujian dilakukan untuk mengetahui seberapa lama waktu yang dibutuhkan untuk menghubungkan ke internet. Pengujian koneksi dilakukan menggunakan beberapa jaringan internet. 
JURNAL MEDIA INFORMATIKA BUDIDARMA

Volume 4, Nomor 1, Januari 2020, Page 117-123

ISSN 2614-5278 (media cetak), ISSN 2548-8368 (media online)

Available Online at https://ejurnal.stmik-budidarma.ac.id/index.php/mib

DOI 10.30865/mib.v4i1.1905

Tabel 2. Hasil pengujian Koneksi Internet

\begin{tabular}{clccc}
\hline No & \multicolumn{1}{c}{ SSID } & $\begin{array}{c}\text { Provide } \\
\mathbf{r}\end{array}$ & $\begin{array}{c}\text { Kecepatan( } \\
\text { Mbps) }\end{array}$ & $\begin{array}{c}\text { Lama } \\
\text { Koneksi } \\
\text { (detik) }\end{array}$ \\
\hline $\mathbf{1}$ & Digisoul & three & 2 & 10 \\
$\mathbf{2}$ & Surba & MNC & 10 & 4 \\
$\mathbf{3}$ & RW & MNC & 10 & 3 \\
& Ciganjur & & & \\
$\mathbf{4}$ & Ionah_plus & MNC & 6 & 5 \\
$\mathbf{5}$ & Buat_TA & Indosat & 1,8 & 12 \\
Rata - rata waktu koneksi & & 6,8 \\
\hline
\end{tabular}

Pada tabel 2 hasil pengujian menghubungkan nodemcu ke internet memiliki lama koneksi yang berbeda beda. Perhitungan waktu koneksi dengan cara menghitung titik pada serial monitor yang sudah diatur dengan delay waktu selama 0,5 detik. Pada percobaan yang dilakukan memiliki waktu koneksi rata rata 6,8 detik. Jika proses koneksi berhasil maka akan muncul seperti pada gambar 4.

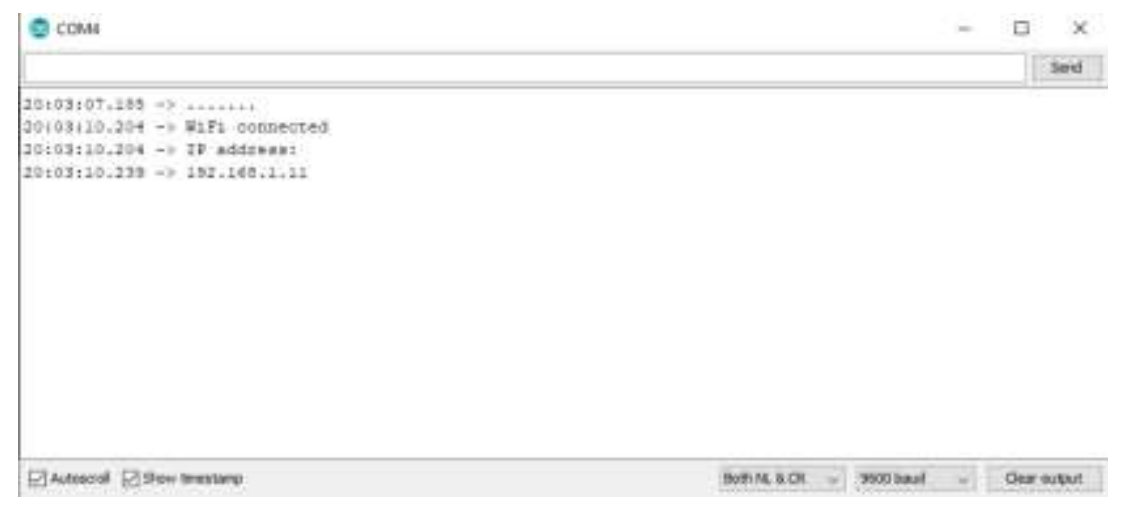

Gambar 4. Proses menghubungkan ke jaringan wifi

\subsection{Pengujian Jarak ketinggian permukaan air dengan sensor ultrasonik}

Pengujian dilakukan untuk mengetahui ketepatan sensor ultrasonik dalam membaca jarak. Ujicoba menggunakan wadah dengan ketinggian $30 \mathrm{~cm}$ dan sensor ultrasonik ditempatkan diatas wadah dengan jarak aman ketinggian 4 $\mathrm{cm}$ dari ketinggian air.

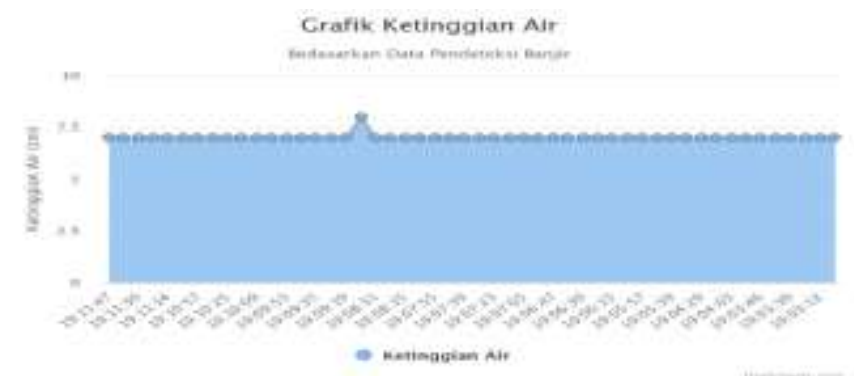

Gambar 5. Grafik pengujian 50 data pertama.

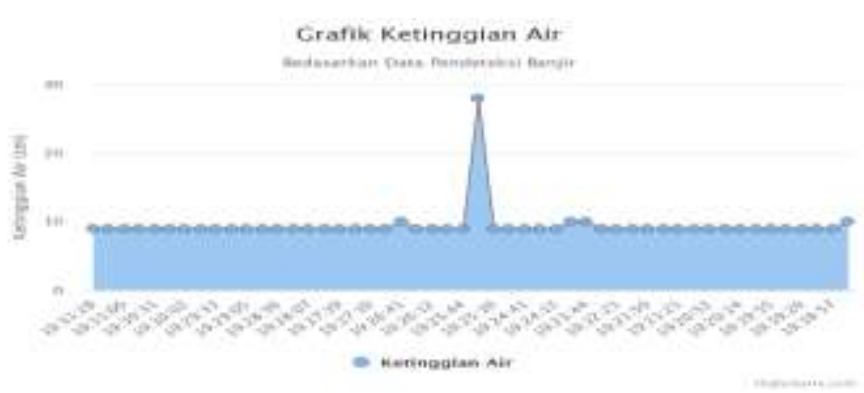

Gambar 6. Grafik pengujian 50 data kedua. 
Pada grafik di atas menunjukan dalam 100 data yang diinputkan dengan 2 kali ujicoba pada ketinggian air yang berbeda terjadi 6 kali kesalahan pembacaan jarak. 50 data pertama dengan ketinggian air $7 \mathrm{~cm}$ terdapat 1 kesalahan dengan nilai kesalahan $1 \mathrm{~cm}$ pada inputan ke 33. Pada 50 data selanjutnya dengan ketinggian air $9 \mathrm{~cm}$ terjadi kesalahan sebanyak 5 kali. Kesalahan pertama terjadi pada inputan pertama dengan nilai kesalahan $1 \mathrm{~cm}$, kesalahan kedua dan ketiga terjadi pada inputan ke 18 dan 19 dengan nilai kesalahan $1 \mathrm{~cm}$, kesalahan keempat terjadi pada inputan ke 25 dengan nilai kesalahan $19 \mathrm{~cm}$, kesalahan kelima terjadi pada inputan ke 30 dengan nilai kesalahan $1 \mathrm{~cm}$.

\subsection{Hasil Pengujian Sistem Database}

Pada pengujian database menggunakan display chart yang terdapat pada phpmyadmin, total data yang diinputkan sebanyak 409 data.

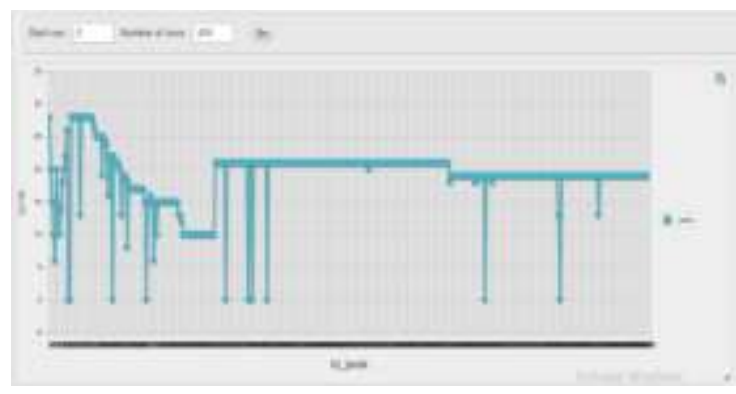

Gambar 7. Grafik database

Gambar grafik diatas menunjukan banyak data yang terdapat di database, menurut data yang ditampilkan terdapat 409 data dan tidak terdapat error dalam penginputan data ke database.

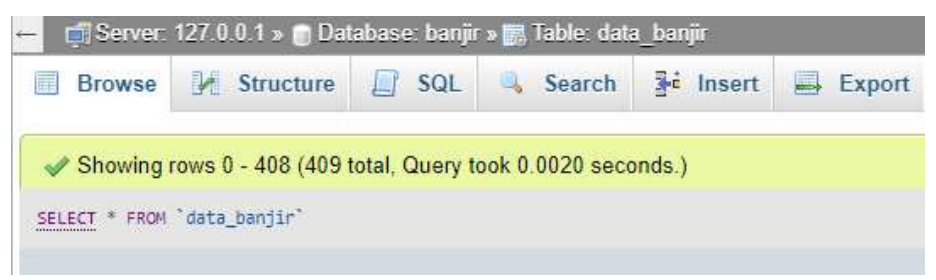

Gambar 8. Waktu tampil data

Pada gambar diatas menunjukan waktu yang dibutuhkan database untuk menampilkan 409 data adalah 0,0020 detik. Ujicoba dilakukan untuk mengetahui apakah data yang dikirim oleh sensor ultrasonik tersimpan ke dalam database sesuai sistem. Data yang telah disimpan di database kemudian akan di tampilkan pada halaman website secara realtime. Rata - rata waktu data yang dikirimkan sensor ke database adalah 5 detik. Perhitungan waktu dibantu dengan alat stopwatch.

\section{KESIMPULAN}

Berdasarkan hasil penelitian dan pengujian yang telah dilakukan maka dapat disimpulkan bahwa koneksi internet yang tinggi dan stabil dibutuhkan agar nodemcu dapat terhubung dengan server. Dari 100 data jarak permukaan air dengan sensor ultrasonik yang telah diujicoba, mendapat 6 kali kesalahan pembacaan jarak dengan nilai kesalahan $1 \mathrm{~cm}$ sebanyak 5 kali dan $19 \mathrm{~cm}$ sebanyak 1 kali. Hasil pengujian sistem dari beberapa data jarak yang diinput,semua data dapat disimpan pada database dan ditampikan pada halaman website secara realtime. Rata rata waktu data yang dikirimkan sensor ke database adalah 5 detik

\section{REFERENCES}

[1] I. Fitri Astuti, A. N. Manoppo, Z. Arifin, and I. Komputer, "SISTEM PERINGATAN DINI BAHAYA BANJIR KOTA SAMARINDA MENGUNAKAN SENSOR ULTRASONIC BERBASIS MIKROKONTROLER DENGAN BUZZER DAN SMS."

[2] I. Handayani, A. Setiadi, and F. N. Iman, "Alat Pengukur Ketinggian Air Berbasis Microcontroller Sebagai Peringatan Banjir Dengan Notification,” Technomedia J., vol. 4, no. 1, pp. 84-97, 2019, doi: 10.33050/tmj.v4i1.896.

[3] E. Lilian and Wildian, "Rancang Bangun Sistem Deteksi dan Informasi Lokasi Banjir Berbasis GSM," vol. 7, no. 4, pp. 328-333, 2018.

[4] Sofyan, C. B. Affianto, and S. Liyan, "Pembuatan Prototipe Alat Pendeteksi Level Air Menggunakan Arduino Uno R3," J. Inf. Interaktif, vol. 1, no. 2, pp. 104-110, 2016.

[5] J. Tarigan and A. D. Betan, "SISTEM PERANCANGAN PENDETEKSI BANJIR SECARA DINI," vol. 2, no. 2, pp. 63-67, 2019. 


\section{JURNAL MEDIA INFORMATIKA BUDIDARMA}

Volume 4, Nomor 1, Januari 2020, Page 117-123

ISSN 2614-5278 (media cetak), ISSN 2548-8368 (media online)

Available Online at https://ejurnal.stmik-budidarma.ac.id/index.php/mib

DOI 10.30865/mib.v4i1.1905

[6] A. Muzakky, A. Nurhadi, A. Nurdiansyah, and G. Wicaksana, "Perancangan Sistem Deteksi Banjir Berbasis IoT," no. September, pp. 660-667, 2018.

[7] E. Rahmadi, A. Nismayanti, and E. Sesa, "Rancang Bangun Prototipe Detektor Banjir Nirkabel Pada Sungai Berbasis Arduino Uno Menggunakan Sel Konduktif Erwan," vol. 15, no. 2, pp. 1-8, 2016.

[8] W. Astuti and A. Fauzi, "Perancangan Deteksi Banjir Menggunakan Sensor Kapastif Mikrokontroler ATMega328p dan SMS Gateway,” J. Inform., vol. 5, no. 2, pp. 255-261, 2018, doi: 10.31311/ji.v5i2.3868.

[9] R. Sulistyowati, H. A. Sujono, and A. khamdi Musthofa, "Sistem Pendeteksi Banjir Berbasis Sensor Ultrasonik Dan Mikrokontroler," pp. 49-58, 2015.

[10] A. Prasetyo and M. B. Setyawan, "Purwarupa Internet of Things Sistem Kewaspadaan Banjir Dengan Kendali Raspberry Pi,” Netw. Eng. Res. Oper., vol. 3, no. 3, pp. 201-205, 2018, doi: 10.21107/NERO.V3I3.97. 